\title{
How to bridge? Management of anticoagulation in patients with mechanical heart valves undergoing noncardiac surgical procedures
}

\author{
Corinne W. Tan, MD, Matthew Wall, MD, Todd K. Rosengart, MD, and Ravi K. Ghanta, MD
}

From the Michael E. DeBakey Department of Surgery, Baylor College of Medicine, Houston, Tex.

No funding was provided for this work.

Received for publication Feb 23, 2018; revisions received June 16, 2018; accepted for publication June 25, 2018; available ahead of print Aug 11, 2018.

Address for reprints: Corinne W. Tan, MD, Michael E. DeBakey Department of Surgery, Baylor College of Medicine, One Baylor Plaza, MC 390, Houston, TX 77030 (E-mail: cortwm@ gmail.com).

J Thorac Cardiovasc Surg 2019;158:200-3

$0022-5223 / \$ 36.00$

Copyright (c) 2018 by The American Association for Thoracic Surgery

https://doi.org/10.1016/j.jtcvs.2018.06.089

An estimated $13 \%$ of patients with mechanical heart valves (MHVs) subsequently require noncardiac surgical operations. ${ }^{1}$ With $140,000 \mathrm{MHVs}$ implanted annually, this patient population continues to expand, and bridging anticoagulation strategies are required.

Although the American Heart Association (AHA) and American College of Cardiology (ACC) and the American College of Chest Physicians (ACCP) provide guidelines on anticoagulation for patients with MHVs, limited guidance is provided for bridging anticoagulation ${ }^{2,3}$ The guidelines are focused on preoperative bridging, with virtually no guidance on postoperative bridging. Consequently, bridging strategies vary widely among physicians, many of whom tend to overestimate thromboembolic risk. The rush to anticoagulate postoperatively commonly results in increased bleeding. Moreover, clinical judgment as well as individualized therapy were recommended in both the AHA and ACC guidelines and the ACCP guidelines. 2,3 We endeavor to present current guidelines for bridging anticoagulation strategies for patients with MHVs undergoing noncardiac surgery, along with additional recommendations that are based on reports of institutional experiences.

\section{RISK OF THROMBOEMBOLISM}

The principal concern with holding anticoagulation is thromboembolism, which carries a $20 \%$ mortality and a $40 \%$ rate of major disability ${ }^{4}$ Thromboembolism is defined as valvular thrombus, stroke, transient ischemic attack, unstable angina, myocardial infarction, or systemic embolism. ${ }^{5,6}$ The estimated annual thromboembolic risk without anticoagulation in a patient with $\mathrm{MHV}$ is $8 \%$ to $22 \%{ }^{4}$ With warfarin, the risk is decreased by $80 \%{ }^{7}$ Current ACCP guidelines and the AHA and ACC guidelines suggest that mechanical aortic valves in the absence of other TE risks should be maintained at a target international normalized ratio (INR) of 2.5, whereas mechanical aortic valves with additional thromboembolic risks and

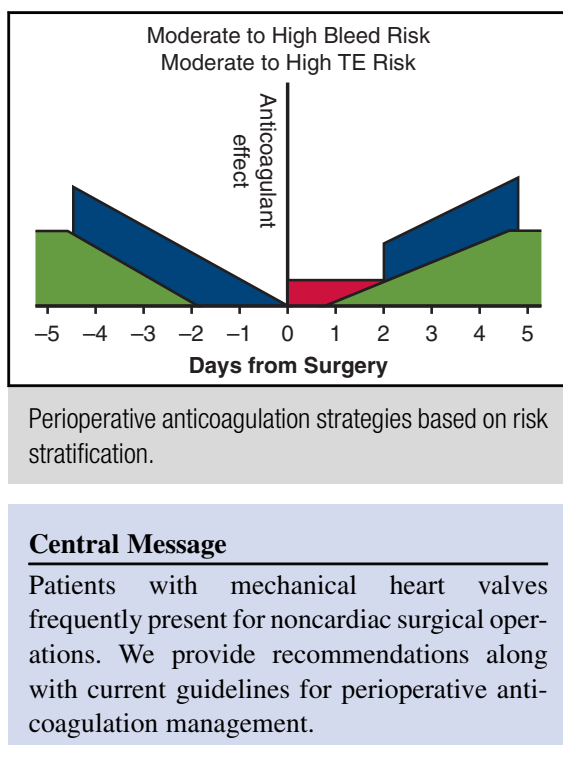

See Commentaries on pages 204 and 206.

mechanical mitral valves should be maintained at a target INR of $3 .^{2,3,7}$ Additional thromboembolic risks include atrial fibrillation, left ventricular ejection fraction lower than $35 \%$, older age, hypercoagulable conditions, and history of previous thromboembolic events. ${ }^{2}$ Thromboembolic risk is also related to valve type and location. The highest thromboembolic risk occurs with double MHVs, followed by mitral MHVs, and the lowest is seen with aortic MHVs. ${ }^{7}$ Newer generation pyrolitic carbon aortic heart valves (On-X; CryoLife Inc, Kennesaw, Ga) have been approved by the US Food and Drug Administration for a reduced target INR of 1.5 to 2 .

\section{RISK OF BLEEDING}

Conversely, bridging regimens increase the risk of major perioperative bleeding by an estimated $4 \%$ to $8 \%$, which is directly correlated to INR. ${ }^{5,6,8,9}$ Major bleeding is defined as a greater than $2-\mathrm{g} / \mathrm{L}$ decrease in hemoglobin, the need for transfusion, or the need for hospitalization or additional intervention to address bleeding. Minor bleeding constitutes bleeding that is self-limited and requires neither hospital admission nor transfusion. Examples include epistaxis, hematoma, and incision site bleeding that does not necessitate withholding anticoagulation therapy. 
Minor bleeding has been estimated to be $15 \%$ perioperatively.

\section{TO BRIDGE OR NOT TO BRIDGE?}

All recent studies evaluating bridging strategies have found that major bleeding occurs more frequently than thromboembolism. ${ }^{2,6,9-11}$ Bleeding to thrombosis ratio is 13:1 in patients who undergoing bridging versus $5: 1$ in those without bridging. Major bleeding may be an acceptable complication to avoid thromboembolism, which may more significantly affect patient's long-term outcomes; however, there is no evidence of meaningful decrease in thromboembolic events when bridging is used. ${ }^{5,10}$ The estimated perioperative risk of symptomatic thromboembolic events in patients with MHVs who undergo bridging is about $0.7 \%$ to $1.2 \%$, ${ }^{6,8}$ with higher rates noted for cage-ball valves and tilting disc valves that have since been retired. ${ }^{1}$ Without bridging, thromboembolic risks are estimated to be about $0.08 \%$ to $0.36 \%{ }^{5}$ The report of thromboembolic events, however, does not analyze the thromboembolism rates in patients with low versus high thromboembolic risk. With the known increased risk of thromboembolic events in patients without anticoagulation, it is unwise to abort bridging strategies completely in patients with moderate to high thromboembolic risks. As with most decisions made by medical practitioners, the risk versus benefit ratio must be weighed.

The AHA and ACC guidelines state that warfarin can be continued without interruption in patients underdoing minor procedures. For major procedures, warfarin can be interrupted for 3 to 4 days preoperatively without bridging in patients with low thromboembolic risk (eg, aortic MHV with no other thromboembolic risks). Bridging should begin when the INR falls below 2 or 2.5 in patients with higher thromboembolic risks (eg, mitral MHV or aortic MHV with additional thromboembolic risks). After the procedure, warfarin should be restarted 12 to 24 hours after surgery or when oral diet is possible. There were no specific guidelines for bridging postoperatively. Moreover, the AHA and ACC guidelines also state that bridging should be individualized and account for the trade-offs between thrombosis and bleeding. ${ }^{2}$ In this article, we seek to augment these guidelines with additional criteria to guide bridging strategies before and after the operation.

Bleeding risks are often dependent not only on the type of procedure but also on specific clinical risk factors. After reviewing more than 2100 patients receiving chronic anticoagulation for various causes, Tafur and associates ${ }^{12}$ established a scoring system called BleedMAP that helps clinician assess bleeding risk based on the basis of 4 clinical variables ( 1 point per variable): history of previous bleeding, mitral MHV, active cancer, and thrombocytopenia 150,000 cells $/ \mu \mathrm{L}$ or less. Without risk factors, rates of major hemorrhage were equivalent between patients who were bridged with low-molecular weight heparin (LMWH) and those who were not. This same group of patients had higher thromboembolism rates than the whole cohort when bridging regimens were not used. Conversely, bleeding rates increased with higher BleedMAP score. Interestingly, thromboembolism rates were nonexistent for patients with a BleedMAP score of at least 3 , and this group of patients had higher bleeding risks when undergoing bridging regimens than when not undergoing such bridging regimens. We incorporate the BleedMAP score in our bridging strategies, as outlined in the following section and in Table 1.

\section{BRIDGING STRATEGY \\ Patient and Procedure Stratification}

We recommend stratifying patients according to thromboembolic risk and bleeding risk, as outlined in Table 1. Patients with low thromboembolic risk are defined as those with bileaflet aortic MHV in normal sinus rhythm and no previous history of thromboembolism. All other patients are categorized as being at moderate to high thromboembolic risk; these include those with mitral MHVs, those with older generation nonbileaflet aortic MHVs, and those with aortic MHVs and additional risk factors (atrial fibrillation, previous thromboembolic event, hypercoagulable state, left ventricular ejection fraction $<35 \%$ ). Bleeding risk is stratified by the nature of the procedure and the BleedMAP score. Minor procedures include endoscopy, percutaneous interventions, dental procedures, arthroscopic surgery, pacemaker placements, among others. All other procedures, or anything that poses a high risk for bleeding in the judgment of the surgeon, would be considered a major procedure. We recommend integrating the BleedMAP score when stratifying patients. Patients with a BleedMAP score of 1 or less have a low bleeding risk, whereas patients with a BleedMAP of at least 2 have a moderate to high bleeding risk.

\section{Preoperative Management}

Our recommended strategy is outlined in Table 1 and Figure 1. Consistent with the AHA and ACC guidelines for patients undergoing procedures with low bleeding risks, no preoperative interruption of warfarin is required. It is also reasonable to continue warfarin but lower the dose to target a lower INR (2.0 instead of 2.5, and 2.5 instead of 3 ). For patients at moderate to high bleeding risk, warfarin should be held 4 days preoperatively. Patients with low thromboembolic risk do not require preoperative bridging, whereas bridging is recommended for patients with moderate to high risk of thromboembolism. LMWH is most frequently used for bridging, except in patients with chronic kidney disease (CKD). The ACCP guidelines in 2012 recommended therapeutic dosing of LMWH instead of unfractionated heparin (UH) for bridging because od its safer 
TABLE 1. Management algorithm based on bleeding and thromboembolic risk

\begin{tabular}{|c|c|c|c|c|}
\hline & \multicolumn{2}{|c|}{$\begin{array}{c}\text { Low bleeding risk } \\
(\text { minor procedure or BleedMAP } \leq 1)\end{array}$} & \multicolumn{2}{|c|}{$\begin{array}{c}\text { Moderate to high bleeding risk } \\
\text { (major procedure or BleedMAP } \geq 2 \text { ) }\end{array}$} \\
\hline & Preoperative & Postoperative & Preoperative & Postoperative \\
\hline \multicolumn{5}{|l|}{ Low TE risk } \\
\hline $\begin{array}{l}\text { Mechanical bileaflet } \\
\text { aortic valve in } \\
\text { normal sinus rhythm }\end{array}$ & $\begin{array}{l}\text { - No interruption of } \\
\text { warfarin or lower } \\
\text { target INR ( } 2 \text { instead } \\
\text { of } 2.5,2.5 \text { instead of } 3)\end{array}$ & $\begin{array}{l}\text { Continue or resume } \\
\text { standard-dose warfarin }\end{array}$ & $\begin{array}{l}\text { - Hold warfarin } 4 \mathrm{~d} \\
\text { before with target } \\
\text { INR }<1.5 \\
\text { - No bridging } \\
\text { heparin or } \\
\text { LMWH }\end{array}$ & $\begin{array}{l}\text { - Resume warfarin once } \\
\text { tolerating oral diet } \\
\text { - No bridging heparin or } \\
\text { LMWH unless unable to } \\
\text { administer warfarin } \\
\text { - Appropriate mechanical and } \\
\text { pharmacologic VTE } \\
\text { prophylaxis }\end{array}$ \\
\hline \multicolumn{5}{|l|}{ Moderate to high TE risk } \\
\hline $\begin{array}{l}\text { - Mechanical mitral valve or } \\
\text { mechanical aortic valve } \\
\text { with additional risk factors } \\
\text { - Hypercoagulable state } \\
\text { - Atrial fibrillation } \\
\text { - Previous TE event } \\
\text { - LVEF }<35 \%\end{array}$ & $\begin{array}{l}\text { No interruption of } \\
\text { warfarin or lower } \\
\text { target INR ( } 2 \text { instead } \\
\text { of 2.5, } 2.5 \text { instead of } 3)\end{array}$ & $\begin{array}{l}\text { - Continue or resume } \\
\text { standard-dose warfarin }\end{array}$ & $\begin{array}{l}\text { - Hold warfarin } 4 \mathrm{~d} \\
\text { before with target } \\
\text { INR }<1.5 \\
\text { - Bridge with LMWH* } \\
\text { - If CKD stage IV or V, } \\
\text { bridge with heparin }\end{array}$ & $\begin{array}{l}\text { Resume warfarin once able } \\
\text { to tolerate oral diet } \\
\text { - Bridging heparin or LMWH } \\
\text { on postoperative day } 2 \\
\text { - Appropriate mechanical and } \\
\text { pharmacologic VTE prophylaxis }\end{array}$ \\
\hline
\end{tabular}

$T E$, Thromboembolic; INR, international normalized ratio; $L M W H$, low-molecular weight heparin; $V T E$, venous thromboembolism; $L V E F$, left ventricular ejection fraction; $C K D$, chronic kidney disease. *Initiate bridging once international normalized ratio is below therapeutic range or 2 days after warfarin has been held.

bleeding profile and its cost efficiency, which is due to the ability to administer it on an outpatient basis. The dosing of the more commonly used LMWH enoxaparin should be twice daily $1 \mathrm{mg} / \mathrm{kg}$ dosing or $1.5 \mathrm{mg} / \mathrm{kg}$ once daily dosing after INR falls below the therapeutic range or 2 days after warfarin has been held, with $0.5 \mathrm{mg} / \mathrm{kg}$ dosing
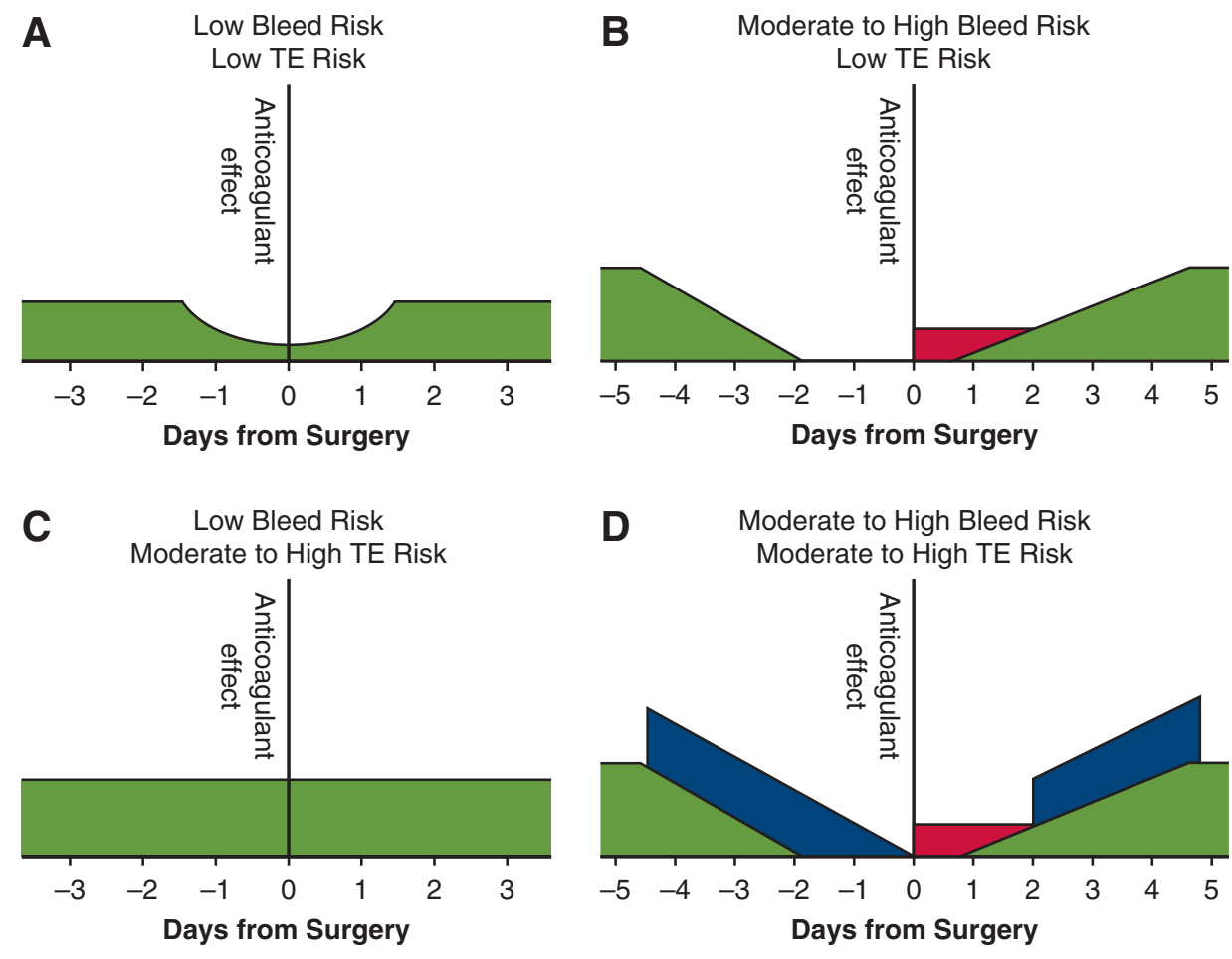

Bridging $\square$ Mechanical \& Pharmacological VTE Prophylaxis $\square$ Coumadin

FIGURE 1. Periprocedural anticoagulation strategies based on thromboembolic and bleeding risks. TE, Thromboembolic; VTE, venous thromboembolism. (Adapted with permission. ${ }^{11}$ ) 
on the morning of the day before the procedure. Patients with CKD stage IV or V and decreased creatinine clearance less than $30 \mathrm{~mL} / \mathrm{min}$ should be bridged with $\mathrm{UH}$, and the heparin drip should be stopped 4 to 6 hours before surgery. ${ }^{3,8}$ If LMWH is still chosen as the agent of choice for a patient with stage IV CKD, dose reduction and monitoring of anti-Xa levels will be needed. Patients with stage V CKD should not receive LMWH. The newer generation On-X aortic valves are bileaflet and approved for a lower INR anticoagulation level. There are no specific studies evaluating bridging anticoagulation in this patient population. It would be reasonable to treat these valve other bileaflet aortic MHVs, albeit with a lower target INR goal (bridging anticoagulation does not need to occur until INR $<1.5$ in the absence of other thromboembolic risk factors).

\section{Postoperative Management}

For patients whose anticoagulation is held, warfarin should be resumed as soon as an oral diet can be tolerated, as early as 12 to 24 hours postoperatively. ${ }^{4}$ For those with moderate to high thromboembolic risk, we recommend the second postoperative day for initiation of postoperative bridging with UH or LMWH. Starting any sooner increases the risk of bleeding significantly. ${ }^{1,8,12}$ For patients who have undergone major operations and in the judgment of the surgeon remain at elevated risk for bleeding, UH may provide less risk of bleeding and greater reversibility than LMWH. Bridging is continued until the INR exceeds the lower limit of the therapeutic range for at least 24 hours. ${ }^{12}$ For all patients, venous thromboembolism prophylaxis is recommended. ${ }^{8}$

\section{CONCLUSIONS}

Although thromboembolic risk in patients with MHVs is a concern, this risk must be balanced with perioperative bleeding risks. Although studies are limited in the MHV population, most have demonstrated that the risk of bleeding far exceeds the risk of thromboembolism with bridging anticoagulation. Our proposed bridging anticoagulation strategy accounts for current guidelines and allows a more individualized approach to anticoagulation in patients with MHV who undergo noncardiac surgical operations. Newer studies are clearly needed, and we look forward to the results from the ongoing A Double Blind Randomized Control Trial of Post-Operative Low Molecular Weight Heparin Bridging Therapy Versus Placebo Bridging Therapy for Patients Who Are at High Risk for Arterial Thromboembolism (PERIOP) 2 randomized controlled trial looking at postoperative bridging with LMWH versus placebo in patients receiving chronic oral anticoagulation.

\section{Conflict of Interest Statement}

Authors have nothing to disclose with regard to commercial support.

\section{References}

1. Carrel TP, Klingenmann W, Mohacsi PJ, Berdat P, Althaus U. Perioperative bleeding and thromboembolic risk during non-cardiac surgery in patients with mechanical prosthetic heart valves: an institutional review. J Heart Valve Dis 1999;9:392-8.

2. Nishimura RA, Otto CM, Bonow RO, Carabello BA, Erwin JP III, Fleisher LA, et al. 2017 AHA/ACC focused update of the 2014 AHA/ACC guideline for the management of patients with valvular heart disease: a report of the American College of Cardiology/American Heart Association task force on clinical practice guidelines. J Am Coll Cardiol. 2017;70:252-89.

3. Douketis JD, Spyropoulos AC, Spencer FA, Mayr M, Jaffer AK, Eckman MH et al. Perioperative management of antithrombotic therapy: antithrombotic therapy and prevention of thrombosis, 9th ed: American College of Chest Physicians evidence-based clinical practice guidelines. Chest. 2012;141(2 Suppl): e326S-50S.

4. Prendergast BD. Management of patients with prosthetic heart valves during non-cardiac surgery. Przegl Lek. 2004;61:556-9.

5. Biteker M, Tekkeşin AI, Can MM, Dayan A, Than E, Türkmen FM. Outcome of noncardiac and nonvascular surgery in patients with mechanical heart valves. Am J Cardiol. 2012;110:562-7.

6. Daniels PR, McBane RD, Litin SC, Ward SA, Hodge DO, Dowling NF, et al. Peri-procedural anticoagulation management of mechanical prosthetic heart valve patients. Thromb Res. 2009;124:300-5.

7. Whitlock RP, Sun JC, Fremes SE, Robens FD, Teoh KH. Antithrombotic and thrombolytic therapy for valvular disease: antithrombotic therapy and prevention of thrombosis, 9th Ed: American College of Chest Physicians evidence-based clinical practice guidelines. Chest. 2012;141(2 Suppl):e576S-600S.

8. Douketis JD. Perioperative anticoagulation management in patients who are receiving oral anticoagulant therapy: a practical guide for clinicians. Thromb Res. 2002;108:3-13.

9. Douketis JD, Spyropoulos AC, Kaatz S, Becker RC, Caprini JA, Dunn AS, et al; BRIDGE Investigators. Perioperative bridging anticoagulation in patients with atrial fibrillation. N Engl J Med. 2015;373:823-33.

10. Siegal D, Yudin J, Kaatz S, Douketis JD, Lim W, Spyropoulos AC. Periprocedural heparin bridging in patients receiving vitamin $\mathrm{K}$ antagonists: systematic review and meta-analysis of bleeding and thromboembolic rates. Circulation. 2012;126:1630-9.

11. Rechenmacher SJ, Fang JC. Bridging anticoagulation: primum non nocere. J Am Coll Cardiol. 2015;66:1392-403.

12. Tafur AJ, Mcbane R II, Wysokinski WE, Litin S, Daniels P, Slusser J, et al. Predictors of major bleeding in peri-procedural anticoagulation management. $J$ Thromb Haemost. 2012;10:261-7. 